\title{
Synthesis of a polycaprolactone-based material with shape-memory and mendability
}

- Tri Minh Phan

- Thuy Thu Truong

- Thanh Dac Nguyen

Polymer Research Center \& Faculty of Materials Technology, Ho Chi Minh City University of Technology, Vietnam National University - HCM.

(Manuscript Received on August 28th, 2015, Manuscript Revised July 06th, 2015)

\begin{abstract}
A new thermoset has been prepared from a bismaleimidic terminated polycaprolactone polyester and a tris-furan compound acting as a crosslinker via the Diels-Alder reaction between the furan and maleimide functionalities. Owing to the reversibility of the Diels-Alder chemistry and the increased mobility of the crosslinked mend scratches under mild temperature conditions. The synthesized precursors and resulting crosslinked material were characterized using ${ }^{1} H$ NMR, FT-IR, GPC, TGA and DSC methods. The scratch mendability of the material was investigated using optical microscopy.
\end{abstract} polyester chains, this material had the ability to

Keywords: Scratch mendability, maleimide, furan, polycaprolactone polyester

\section{INTRODUCTION}

Nowadays, the application of polymeric coatings not only gives better processability but also provides a good protection due to their barrier properties [1]. Nevertheless, these materials are easily damaged when continuously exposed to the external environment, such as mechanical attack, chemical abrasion, UV radiation, or a combination of these factors. Small defects are easily created in the coatings, but difficult or impossible to be detected and repaired. The presence of microcracks can adversly change the coating final properties, and can even develop further into damage which considerably shortens material lifetime.

In recent decades, various self-mending approaches have been developed rapidly, including microencapsulation, microvascular networks, supramolecular self-assembly and reversible chemistry [2]. Among these approaches, intrinsic remendable polymeric systems, which contain reversible covalent bonds, is a particularly attractive one. These polymer networks have repeatedly mending ability to repair the damage at the same position. The most prominent pathway is based on the 
Diels-Alder (DA) reaction [3,4]. DA reactions occur between a diene and a dienophile at a temperature range from room temperature to 80 ${ }^{\circ} \mathrm{C}$ and can be reversed, via the retro-Diels-Alder (rDA) reaction at temperatures above $100{ }^{\circ} \mathrm{C}$, yielding the original diene and the dienophile. This provides sufficient mobility to the network so as to flow locally and to repair surface microscratches. Thus, DA moieties allow the implementation of mending capabilities to polymeric networks without significantly compromising the original material properties [5].

On the other hand, polycaprolactone polyester (PCL) is a very attractive polymer due to its sustained biodegradability, low cost, and availability. The cross-linking of homo- and copolymers of PCL often leads to superior mechanical properties of these materials, such as high modulus and dimensional stability [6].

Therefore, in this paper, a polymer network was synthesized by the DA reaction between the maleimide moieties of a bismaleimidic polycaprolactone polyester and the furan groups of a tris-furan compound, and its scratch mendability was evaluated.

\section{EXPERIMENTAL}

\subsection{Materials}

Hexamethylene diisocyanate (HDI) (99\%), 2-furfurylthiol (97\%), triethylamine (99\%) and zirconium(IV) acetylacetonatewere purchased from Sigma-Aldrich. $n$-Heptane (99+\%), chloroform $(99+\%)$, tetrahydrofuran (THF, $99.5+\%)$ and toluene $(99+\%)$ were purchased from Fisher Chemicals. Hexamethylene diisocyanate isocyanurate trimer (Desmodur ${ }^{\circledR} \mathrm{N}$ 3390 BA) was received from Bayer. 3-
Maleimido-1-propanol was prepared according the previously reported procedure [7]. Poly(caprolactone) diol (PCL, $\mathrm{M}_{\mathrm{n}}=2100 \mathrm{~g} / \mathrm{mol}$ ) was purchased from Acros).

\subsection{Synthesis of bismaleimidic polycaprolactone}

HDI (2.0 mL, $12.4 \mathrm{mmol}), \quad$ freshly azeotropically dried PCL diol (13.15 g, 6.2 mmol) and zirconium(IV) acetylacetonate (121 $\mathrm{mg}, 1 \mathrm{~mol} \%$ per OH group) were dissolved in 160 $\mathrm{mL}$ of dry chloroform under nitrogen atmosphere. The reaction was refluxed for $6 \mathrm{~h}$. After the mixture was cooled down, 3maleimido-1-propanol (1.93 g, $12.4 \mathrm{mmol}$ ) was added and the mixture was again refluxed. After $2 \mathrm{~h}$, the reaction was kept at room temperature overnight under nitrogen atmosphere to assure that all-NCO groups were consumed. After the reaction, chloroform was removed. The product was re-dissolved in THF and precipitated into distilled water. The precipitate was washed with diethyl ether and dried under vacuum. Yield: $80 \%$.

\subsection{Synthesis of tris-furan}

$42.513 \mathrm{~g}$ (155.6 mmol of NCO groups) of Desmodur N3390 BA was mixed with $20 \mathrm{~mL}$ (198.3 mmol) of 2-furfurylthiol in $110 \mathrm{~mL}$ of THF. Triethylamine $(277 \mu \mathrm{L})$ was then added and the reaction was stirred at room temperature overnight. The product was precipitated into $n$ heptane, filtered and dried under vacuum to give a brown solid. Yield: $92 \%$.

2.4. Synthesis of the network from the bismaleimidic polycaprolactone and trisfuran

A mixture of bismaleimidic polycaprolactone and tris-furanin a 1:1 furan to maleimide equivalent ratio in tetrahydrofuran was cast in a glass petri disk at $40{ }^{\circ} \mathrm{C}$ for $48 \mathrm{~h}$, followed by vacuum dried at $60^{\circ} \mathrm{C}$ for $24 \mathrm{~h}$. 


\subsection{Characterization}

${ }^{1} \mathrm{H}$ NMR spectra were recorded in deuterated chloroform $\left(\mathrm{CDCl}_{3}\right)$ with TMS as an internal reference, on a Bruker Avance 300 at $300 \mathrm{MHz}$. Transmission Fourier transform infrared (FT-IR) spectra, collected as the average of 128 scans with a resolution of $4 \mathrm{~cm}^{-1}$, were recorded from $\mathrm{KBr}$ disk on the FT-IR Bruker Tensor 27. Attenuated total reflectance (ATR) FT-IR spectra were collected as the average of 128 scans with a resolution of $4 \mathrm{~cm}^{-1}$ on a FT-IR Tensor 27 spectrometer equipped with a Pike MIRacle ATR accessory with a diamond/ZnSe element. Size exclusion chromatography (SEC) measurements were performed on a Polymer PL-GPC 50 gel permeation chromatograph system equipped with an RI detector, with chloroform as the eluent at a flow rate of $1.0 \mathrm{~mL} / \mathrm{min}$. Molecular weight and molecular weight distribution were calculated with reference to polyethylene glycol standards. Differential scanning calorimetry (DSC) measurements were carried out with a DSC Q20 V24.4 Build 116 calorimeter under nitrogen flow, at a heating rate of $10{ }^{\circ} \mathrm{C} / \mathrm{min}$, from -40 to $170{ }^{\circ} \mathrm{C}$. Thermogravimetric analysis (TGA) measurements were performed under nitrogen flow using a NETZSCH STA 409 PC Instruments with a heating rate of $10{ }^{\circ} \mathrm{C} / \mathrm{min}$ from ambient temperature to $900{ }^{\circ} \mathrm{C}$. Optical microscopic images were recorded on an Olympus GX51F microscope.

\section{RESULTS AND DISCUSSION}

3.1. Synthesis of bismaleimidic polycaprolactone
Polycaprolactone diol $\left(\mathrm{M}_{\mathrm{n}}=2100 \mathrm{~g} / \mathrm{mol} ; 1\right.$ equivalent) was reacted with hexamethylene diisocyanate ( 2 equivalents) via the $\mathrm{OH}-\mathrm{NCO}$ reaction, catalyzed by zirconium(IV) acetylacetonate, to give diisocyanate terminated polycaprolactone. This intermediate product was further reacted with 2 equivalents of 3maleimido-1-propanol by the $\mathrm{OH}-\mathrm{NCO}$ reaction which was catalyzed by zirconium(IV) acetylacetonate. The unreacted 3-maleimido-1propanol was removed by precipitation of the resulting polymer in water (3-maleimido-1propanol is soluble in water). As a result, polycaprolactone containing two maleimide moieties at the polymer chain ends was obtained. The ${ }^{1} \mathrm{H}$ NMR spectrum of this maleimideterminated polycaprolactone is shown in Figure 1 , with all the peaks assigned to its chemical structure. The presence of the urethane (OCONH) peak and at $4.7 \mathrm{ppm}$ and maleimide peak at $6.73 \mathrm{ppm}$ indicates the successful occurrence of the $\mathrm{OH}-\mathrm{NCO}$ reactions and incorporation of maleimide moieties. The FT-IR spectrum of the product in Figure 2 shows the complete disappearance of the NCO group at $2270 \mathrm{~cm}^{-1}$ and the presence of typical maleimide absorption bands at 837 and $697 \mathrm{~cm}^{-1}$ [8], confirming that the maleimide groups were attached to the polycaprolactone chains. The number-average molecular weight $\left(M_{n}\right)$ and molecular weight distribution of this product as determined by SEC were $3800 \mathrm{~g} / \mathrm{mol}$ and 1.4, respectively.

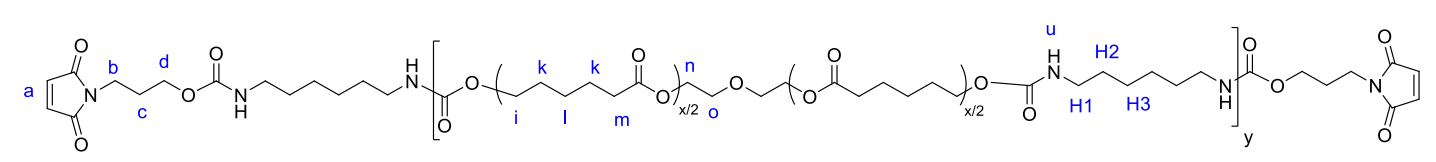




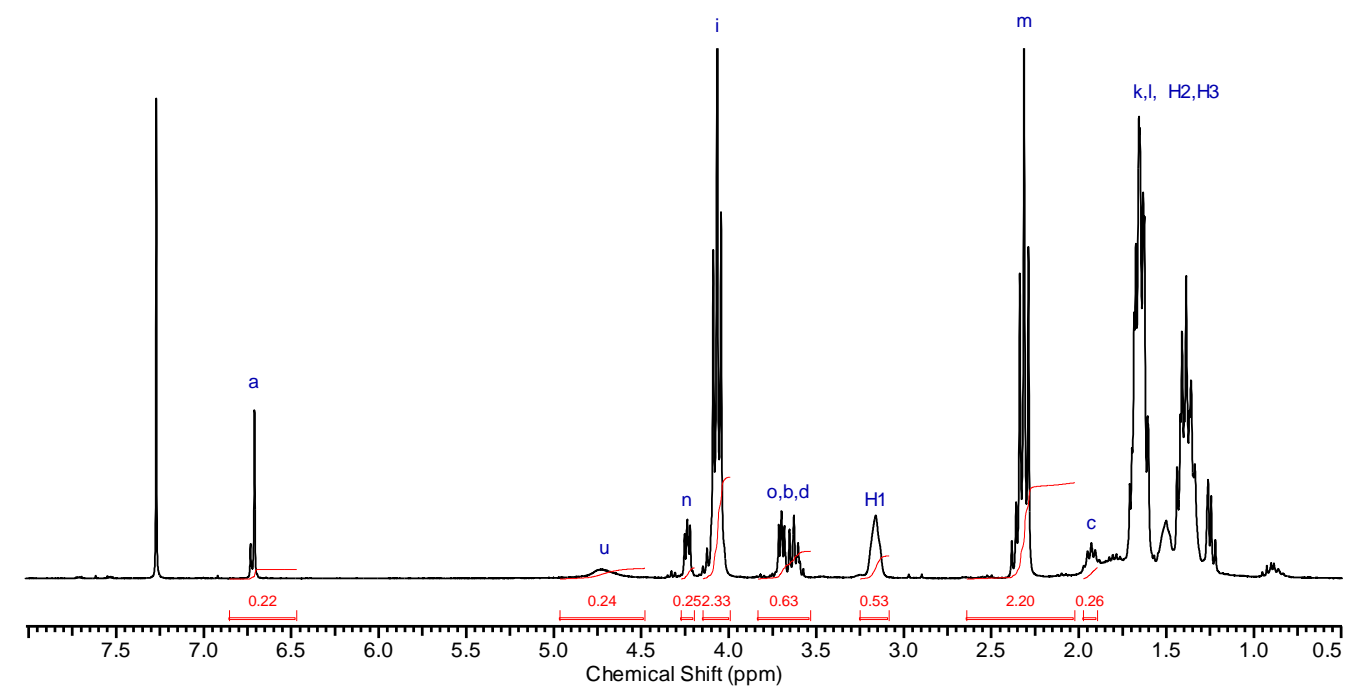

Figure 1. ${ }^{1} \mathrm{H}$ NMR spectrum of bismaleimidic polycaprolactone.

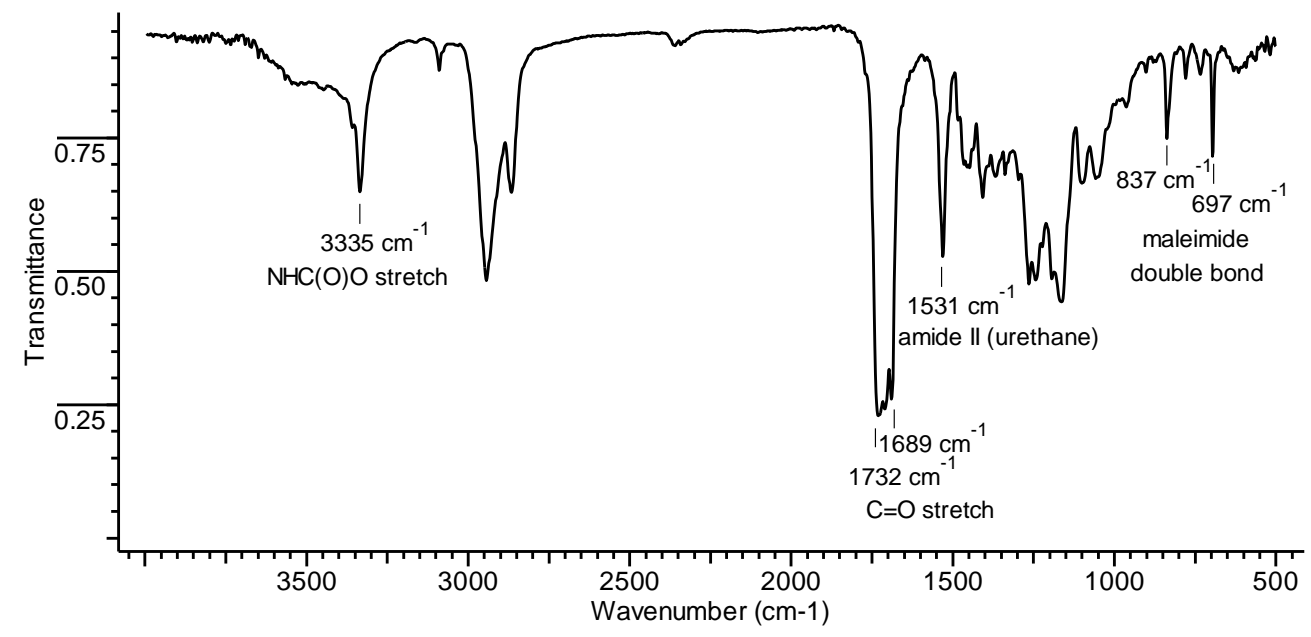

Figure 2. Transmission FT-IR spectrum of bismaleimidic polycaprolactone.
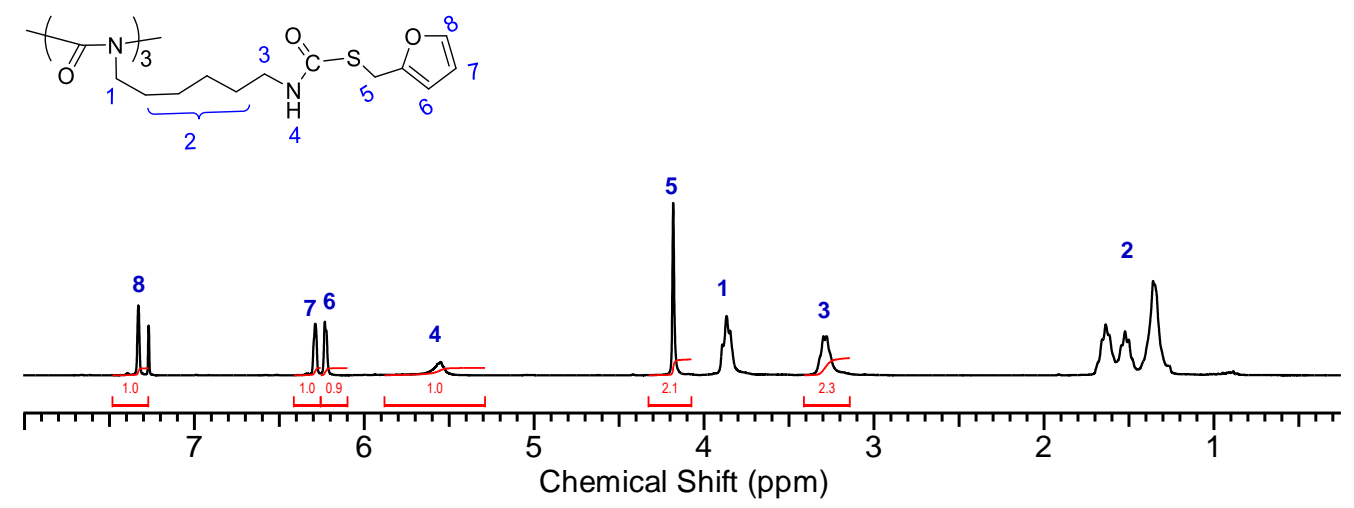

Figure 3. ${ }^{1} \mathrm{H}$ NMR spectrum of tris-furan. 


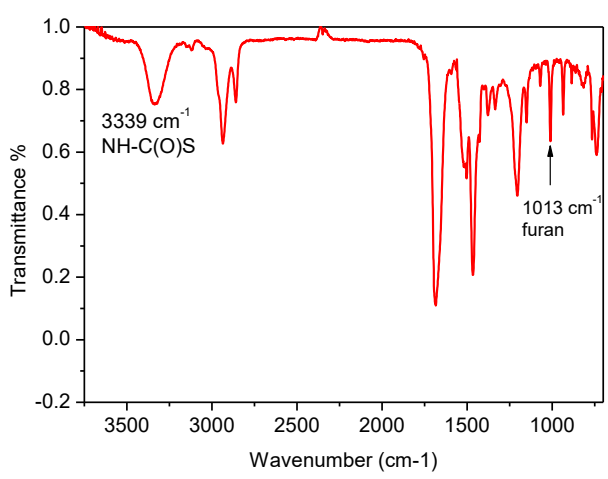

Figure 4. Transmission FT-IR spectrum of trisfuran.

\subsection{Synthesis of tris-furan}

Tris-furan was synthesized by the thiolisocyanate reaction of 2-furfurylthiol and the hexamethylene diisocyanate isocyanurate trimer compound bearing three isocyanate functionalities. As a result, the product containing three furan moieties was obtained. As shown in the ${ }^{1} \mathrm{H}$ NMR spectrum in Figure 3 of this product, all the peaks characteristic of its chemical structure can be assigned. The appearance of the furan peak at 6.21, 6.29 and $7.32 \mathrm{ppm}$ and the thiourethane peak at $5.54 \mathrm{ppm}$ indicates the successful incorporation of the furan groups into the structure of the isocyanurate trimer via the thiourethane formation reaction. This result was confirmed by transmission FT-IR analysis. As shown in Figure 4, the band corresponding to the $\mathrm{NCO}$ group at $2270 \mathrm{~cm}^{-1}$ disappears completely, the band at $3390 \mathrm{~cm}^{-1}$ attributed to the vibration of thiourethane groups appears, and the IR absorption band at $1013 \mathrm{~cm}^{-1}$ was assigned to the signals of the furan functionality [8].
3.3. Characterization of the network formed from bismaleimidic polycaprolactone and tris-furan

The network was created by the crosslinking DA reaction between the furan and maleimide moieties (Scheme 1).

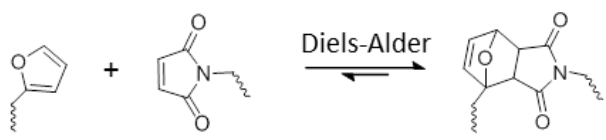

Scheme 1. Diels-Alder (DA) reaction between maleimide and furan groups.

The occurrence of the DA reaction was confirmed by the FT-IR result. Because the obtained material was in the form of a crosslinked solid, transmission FT-IR analysis using $\mathrm{KBr}$ disks could not be conducted. Instead, ATR FTIR was performed. It should be noted that characteristic IR absorption bands of maleimide, furan and DA groups appear at similar wavenumbers in both FT-IR methods. Thus, the spectra recored by both methods could be qualitively compared. As shown in the ATR FTIR spectrum of the material in Figure 5, the almost disappearance of the maleimide bands at 828 and $696 \mathrm{~cm}^{-1}$ as well as the furan bands at $1011 \mathrm{~cm}^{-1}$ suggests the nearly complete reaction between furan and maleimide to form DA-adduct bonds. 


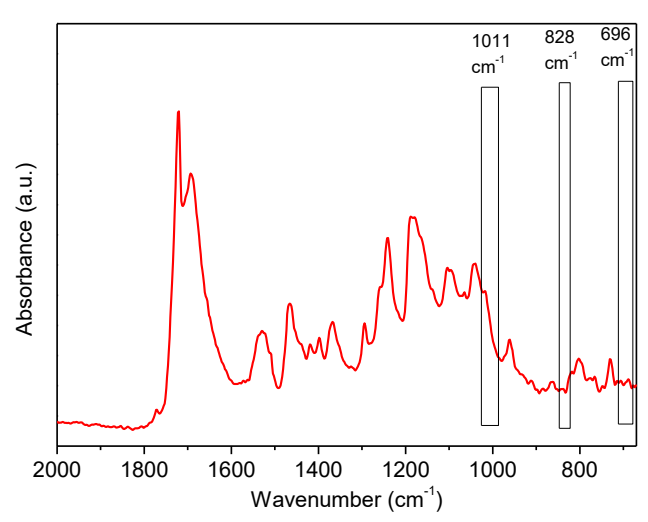

Figure 5. ATR FT-IR spectrum of the crosslinked network.

The TGA analysis result of the cast crosslinked film showed that the polymer network was stable up to above $200{ }^{\circ} \mathrm{C}$ (Figure 6a), while the thermal reversibility of the DA crosslink bonds was attested by DSC analysis. The first DSC heating scan (Figure 6b) showed a large endothermic region from 20 to $60{ }^{\circ} \mathrm{C}$ attributed to the melting of the crystallized PCL segments, and another endothermic peak starting at around $90-100{ }^{\circ} \mathrm{C}$ attributed to the $\mathrm{rDA}$ reaction, indicating the cleaving of cross-linked bonds [8]. The melting temperature of $60 \mathrm{oC}$ of PCL segments is attratibuted to the switching temperature for the shape-memory behavior to occur. The samples were subsequently quenched in liquid nitrogen to avoid the re-formation of DA bonds upon cooling. The second scan included a PCL crystallization exotherm at $-15^{\circ} \mathrm{C}$, followed by a PCL melting peak at $45{ }^{\circ} \mathrm{C}$. An exothermic peak from approximately 60 to $120{ }^{\circ} \mathrm{C}$ was observed and was followed by an endothermic peak at above $125^{\circ} \mathrm{C}$. These two transitions were attributed to the cross-linking and cleaving transitions via the DA and rDA reactions, respectively [9]. These transition temperatures were in the same range as previously reported for DA cross-linked materials $[9,10]$. The appearance of these two DA and rDA transitions in the second scan suggested that the quenched samples contained disconnected furan and maleimide moieties, which re-connected when the molecules gained sufficient mobility at increased temperatures. Compared to the first scan, the smaller area of the rDA endotherm in the second scan represents the lower relative content of DA netpoints in the material due to the shorter reaction time.

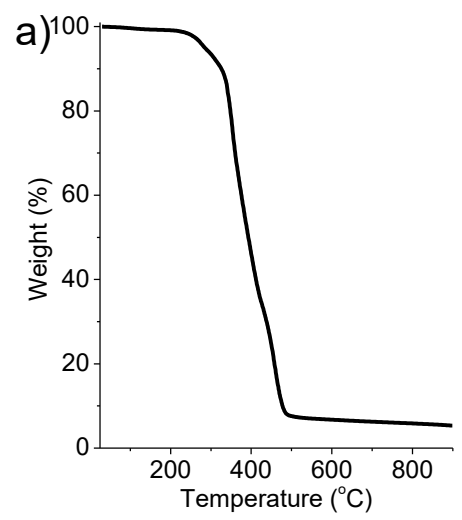

b)

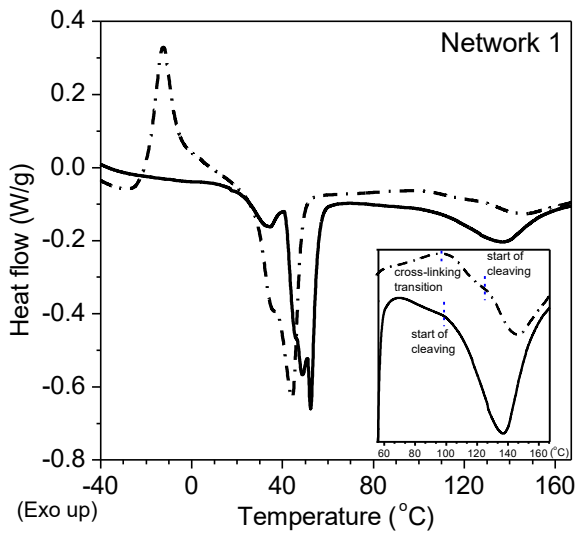


Figure 6. TGA (a) and DSC (b) thermograms (solid line: first heating scan; dash-dotted line: second heating scan; inset: zoom-in of the transitions at $60-170{ }^{\circ} \mathrm{C}$ ) of the crosslinked network .
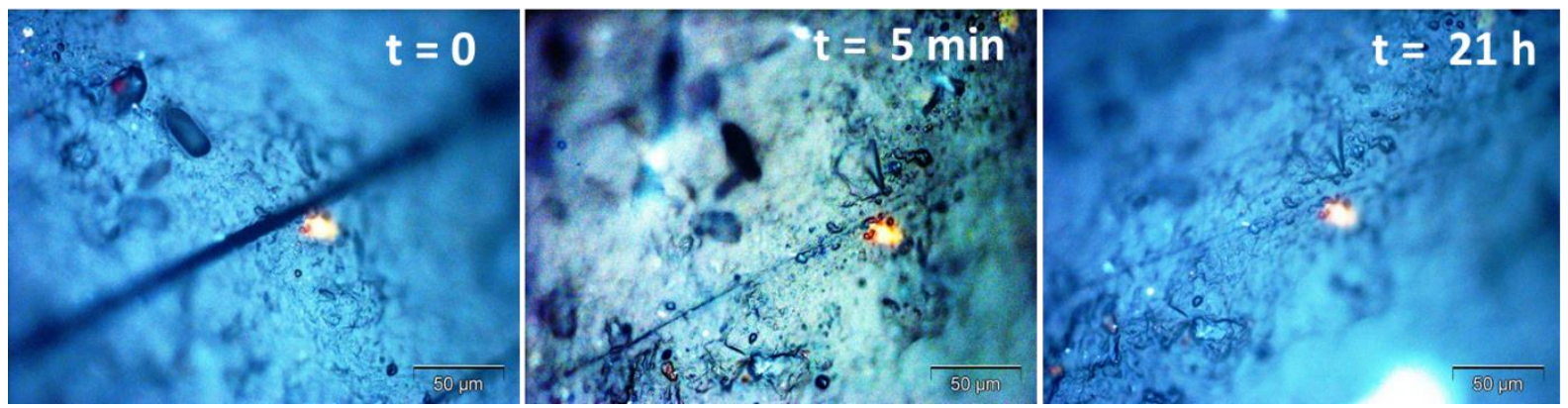

Figure 7. Optical micrographs of scratches of the network sample before $(\mathrm{t}=0)$ and after healing at $60{ }^{\circ} \mathrm{C}$ for $5 \mathrm{~min}$ and $21 \mathrm{~h}$.

\subsection{Assessment of the scratch mendability}

To assess the scratch mendability of the obtained network, a scratch was made in the coating using a razor blade. Afterward, the scratch was repaired by heating the scratched coating sample at $60{ }^{\circ} \mathrm{C}$. At this temperature, the polycaprolactone segments melt, leading to an activation of the chain entropy. Thus, the material gain sufficient local mobility, so that the reversible reaction between the furan and maleimide moieties at the scratch interface could occur. On the other hand, the reformation of the broken DA bonds is favored at $60{ }^{\circ} \mathrm{C}[10]$. As seen in the optical microscopic images in Figure 7 , the scratch was considerably reduced by heating the sample at $60{ }^{\circ} \mathrm{C}$ for $5 \mathrm{~min}$. After $21 \mathrm{~h}$ at $60{ }^{\circ} \mathrm{C}$, the scratch almost healed, with only a scar due to interface mismatch.

\section{CONCLUSIONS}

A polymer network with scratch mendability at mild temperature conditions was successfully prepared via the Diels-Alder reaction between a bismaleimidic polycaprolactone and a tris-furan compound. Remendability was achieved by combining the occurrence of two processes at $60{ }^{\circ} \mathrm{C}$ : an increase in polymer chain mobility, triggered by the melting of the crystallized polycaprolactone phase, brought the free furan and maleimide moieties together, after which a progressive Diels-Alder reaction could reform the covalent bonds on a longer time scale.

Acknowlegments: This research is funded by Ho Chi Minh City University of Technology Vietnam National University, under the project "Fabrication of polyester-based shape-memory polymers crosslinked by UV light" under grant number TSĐH-2015-CNVL-48. 


\section{Tổng hợp polymer trên cơ sở polycaprolactone có khả năng nhớ hình và tự lành}

- Phan Minh Trí

- Trương Thu Thủy

- Nguyễn Đắc Thành

Trung tâm nghiên cứu vật liệu Polymer \& Khoa Công nghệ Vật liệu, Đại Học Bách Khoa-Đại Học Quốc Gia Tp. Hồ Chí Minh.

\section{TÓM TẮT}

Một loại polymer nhiệt rắn mói được tổng nối mạng, vật liệu này có khả năng phục hồi vết hơp tù polyester polycaprolactone mang nhóm bismaleimide ở cuối mạch và tris-furan, chúng liên kết với nhau nhờ phản ứng Diels-Alder giũa cặp nhóm chức furan và maleimide. Tris-furan đóng vai trò là một tác nhân nối mạng. Nhò̀ vào khả năng phản ứng thuận nghịch của nhóm trầy xuớc trong điều kiện nhiệt độ không cao. Các tiền chất tổng hợp và kết quả là polymer nối mạng được phân tích bằng các phuoong pháp ${ }^{1} H$ NMR, FT-IR, GPC, TGA và DSC. Quá trình phuc hồi vết trầy xuớc của vật liệu đã được quan sát bằng kính hiển vi quang học.

Diels-Alder và tính linh động của mạch polyester

Tù khóa: hồi phục vết nút, maleimide, furan, polycaprolactone polyester

\section{REFERENCSES}

[1] Lutz, A., van den Berg, O., Van Damme, J.,

[4] Liu, Y.-L., Chuo, T.-W., Polym. Chem., 2013, Verheyen, K., Bauters, E., De Graeve, I., Du Prez, F. E., Terryn, H., ACS Appl. Mater. Interfaces, 2014, 7, 175-183.

[2] Billiet, S., Hillewaere, X. K. D., Teixeira, R. F. A., Du Prez, F. E., Macromol. Rapid Commun., 2013, 34, 290-309.

[3] Zhang, M. Q., Rong, M. Z., Polym. Chem., 2013, 4, 4878-4884.

$$
\text { 4, 2194-2205. }
$$

[5] Tasdelen, M. A., Polym. Chem., 2011, 2, 2133-2145.

[6] Wang, S., Yaszemski, M. J., Gruetzmacher, J. A., Lu, L., Polymer, 2008, 49, 5692.

[7] Narita, M., Teramoto, T., Okawara, M., Bull. Chem. Soc. Jpn., 1971, 44, 1084-1089. 
[8] Rivero, G., Nguyen, L.-T. T., Hillewaere,

[10] Chen, X., Dam, M. A., Ono, K., Mal, A., X. K. D., Du Prez, F. E., Macromolecules, Shen, H., Nutt, S. R., Sheran, K., Wudl, F., 2014, 47, 2010-2018. Science, 2002, 295, 1698-1702.

[9] Heo, Y., Sodano, H. A., Adv. Funct. Mater., 2014, 24, 5261-5268. 